\title{
Universiteit
}

Leiden

The Netherlands

\section{Mobile mapping and play}

Lammes, S.; Wilmott, C.; Hjorth, L.; De Souza e Silva, A.; Lanson, K.

\section{Citation}

Lammes, S., \& Wilmott, C. (2020). Mobile mapping and play. In L. Hjorth, A. De Souza e Silva, \& K. Lanson (Eds.), The Routledge companion to mobile media art (pp. 202-213). New York: Routledge. doi:10.4324/9780429242816-25

Version:

Publisher's Version

License:

Licensed under Article 25fa Copyright Act/Law (Amendment Taverne)

Downloaded from: $\quad \underline{\text { https://hdl.handle.net/1887/3242816 }}$

Note: To cite this publication please use the final published version (if applicable). 


\title{
19
}

\section{MOBILE MAPPING AND PLAY}

\author{
Sybille Lammes and Clancy Wilmott
}

Art practices, mapping and play have a shared history that harkens back to the creation of the earliest maps, from more recent examples across the playful symbolism of pictorial cartographies, the cartographic play of the Situationiste Internationale (SI) to the maps used in geographic board games from the early modern period. ${ }^{1}$ However, the beginning of this millennium signalled a new turn in this relationship, as digital mapping technologies became more widespread, reshaping mobilities and offering alternative modes of play using wayfinding and digital location. Mobile mapping practices leveraging locative technologies (such as global positioning systems) became a field for experimentation by artists such as Esther Polak, Blast Theory and Mark Hansen using GPS traces to make images from the urban form.

These artists were seen as a new wave of so-called locative $\operatorname{artists}^{2}$ that used mobile digital media in new inventive ways and experimented with the new affordances of mobile mapping. In particular, as the hybridization of maps, spaces and bodies was enabled through GPS location by linking the physical location of the user with a near-real-time digital coordinate, the possibility of putting the moving user in the map in situ became a key site of exploration either using mobility to affect the map, or the map to affect mobility. As MacDonald has argued, such artistic practices often reflected upon the temporality of movement of the user, whether as artist or invited participant. ${ }^{3}$ For example, Polak's and Kee's 2002 project Amsterdam Real Time (with Waag Society), mapped the traces of way-finders in Amsterdam, rendering a colourful image that highlighted how movement through the inner city takes on the shape of a spider-like web. ${ }^{4}$

Since then, many creative experiments have become part of mainstream platforms, as people make their own figures with running apps (such as Strava), leave their traces on OpenStreetMap while participating in amateur mapping parties or use bespoke maps for catching Pokémon. Yet with the proliferation of popular mobile mapping practices, the relation between art and mobile mapping has not ceased to exist but instead has just become more dispersed to a more general user population, and out of the confines of the art gallery. As this chapter discusses, we now see mobile mapping used in playful ways in a wide range of creative cultural practices.

In this chapter, we consider such practices through the lens of mobile mapping as play. Central to our argument is that digital mobile mapping has rather literally brought play into the map object itself. Through the reciprocal movement of map user and of the map image, we foreground the playful affordances of the map and mobile mapping interfaces as central to artistic mapping practices.

Play is, as Huizinga ${ }^{5}$ claimed, one of the main forces of the human creative condition. Huizinga was also a technological pessimist, believing that with the advent of mechanization, play would 
disappear, and "civilization" would be consequently doomed. Yet, what we have seen instead in this millennium is not so much a decline of play, but rather a dispersion of play and a hybridization of play with (post)digital technologies such as smart watches, phones and tablets. This has become even more apparent since the emergence of mobile and ubiquitous technologies that allow us to engage with play “on the go," whether it concerns travelling to work, waiting for a bus or running through a park. This intermingling of spatiality, mobility and play comes as no surprise as play is predominantly about the spatial exploration of and moving through space. ${ }^{6}$

Thus, play and mobility have the affordances to merge easily, and this connection has been promulgated since the emergence of wearable and mobile technologies. Also related to this potential of play to invite experimental spatial exploration is the close relation between mapping and play. As we have argued elsewhere- and counterintuitive to the belief that play is frivolous and mapping rational-mapping and playing have always been practised together, whether in analogue activities such as board games, orienting or geo-caching, or other forms of digital location-based games. ${ }^{7}$

In this chapter, we focus on how ludic mobile mapping can be understood as a creative practice, drawing on an approach to play as fostering creativity. ${ }^{8}$ As Sutton-Smith argues, play and playthings (toys, materials) are often the instigators of creative thinking and problem solving. ${ }^{9}$ Maybe through its ambiguity play can be a lever to make mapping into simultaneously a playful and mobile practice, while setting up an assemblage in which artistic relations between mapping, mobility and play are explored..$^{10}$ Play, in the words of play-scholar Miguel Sicart, "is brought by people to the complex interrelations (...) between things that form daily life," and "to play is, then, to assemble a number of actors to re-create a world." "11,12 It is therefore a state of being, doing and knowing that we can bring to many cultural settings, including that of mobile media art and mapping.

In a similar vein, mobile mapping can be broadly understood as a situated, interpretative practice of working between cartographic, spatial and embodied knowledge. ${ }^{13}$ Specifically, mobile mapping refutes the easy distinction between maps and mappers, and underscores the roles that relationality, movement and entanglements play in the process of navigation, exploration and wayfinding. In doing so, it understands both space-in the form of materialities, flows and processes-and maps-in the form of representations, symbology and data- to have a priori political impacts which are engaged, rearranged, reformed or transformed through moments of mapping. For instance, a person opening a geolocative mobile phone app at a particular point in space and time might simultaneously entangle the spatial politics of where they are (e.g. dispossession, gentrification), the technological politics of what they are mapping with (e.g. data ethics, infrastructures), and the bodily politics of who they are (positionality, experience, embodiment, memory). In this entanglement, mobile mapping can be understood as a relatively radical move away from classic post-structuralist cartographic theory towards an account of mapping which is more performative, material and more-than-cartographic. ${ }^{14,15,16}$

Analysing mobile mapping is crucial to understanding mobile media art, which often engages the embedded, spatial, and movement-oriented aspects of artistic practice. The framework of mobile mapping offers the theoretical and critical ability to extend analysis beyond the artwork into the geographical and historical situatedness of the project: if mobile media art comes into being through movement and location, then where, when and who also matter. In short, the same mobile media artwork performed in two cities might be engaged differently because of their architectural, spatial and cultural specificities. At the same time, the same artwork performed across the same city by different people at different times will also emerge differently due to shifts in weather, light, social crowds, personal histories, memories, technological ability, mood, etc. Thus, no two entanglements are ever fully the same-even where continuous threads of dissent, resistance and hegemony may be traced through multiple spaces and times.

Furthermore, the emphasis on arranging and moving within a mobile mapping framework underscores the playful affordances of mapping itself. ${ }^{17}$ Play, in this context, does not diminish the 
political nature of space and spatiality, but rather opens up the possibility for radical reimaginings and wanderings through everyday spaces. The assembling and reassembling of actors in mobile, situated and mediated ways is precisely where mobile mapping and play begin to intersect. Arguably, mapping is always potentially playful and mobile as it is a practice of drawing things, objects, lines and spaces together. ${ }^{18}$

In addition, play reveals the affordances of the technological, social, and spatial entanglements within mobile mapping, as objects break or are repurposed, people learn, unlearn, remember and re-envision, and materialities weather, morph, or disrupt. Here, Serres' notion of the quasi-object becomes a crucial theoretical tool to both comprehend the relationship between mobile mapping and play. ${ }^{19}$ The quasi-object becomes through its relationality with other things and other actors. Thus, mobile mapping and play as situated, performative and disruptive bedfellows open up possibilities for engaging with mobile media art in unexpected, unanticipated and often transformative ways.

In this chapter, we consider how technological affordances and the quasi-object might render a critical reading of mobile mapping and play. We will do so first by outlining some of the nuances of Serres' theory of the quasi-object, as well as how it sits within the concept of relationality that is widely under debate in science and technology studies, new media studies and geography. Then, we unpack our reading of mobile mapping and play through the quasi-object by closely analysing two case studies: Bee in the City, created by Wild in Art and Manchester City Council in 2018, and the Wayfinder Live project, created by Troy Innocent in 2019-are specific cases of largescale public artworks requiring mobile phones. Because of their public appeal, their technological (rather than say, solely critical or artistic) distinction and their eschewal of traditional gallery spaces, these two cases provide concrete examples of both mobile mapping and playful affordances in public, as objects that sit in place, yet invite certain actions from passers-by, while also being mapped as specific routes through which to navigate the city.

\section{Serres and the Quasi-Object}

Being or relating, that is the whole question. ${ }^{20}$

As the above quote suggests, the quasi-object is neither really object or subject and goes beyond this dichotomy. A subject, writes Serres, ${ }^{21}$ acts and moves objects along. An object, in comparison, is enclosed, absolute and defined. The quasi-object dismantles these Cartesian distinctions, by inviting activity, but not being made only from it.

The ball is perhaps the most recognizable example of how Serres understands quasi-objects. It is also an interesting example in the context of this chapter, as it is at once a playful and mobile "thing." In Serres' estimation, the ball on its own is "dumb" and still, it has no purpose and no action. Yet, when engaged in a team sport or collective activity, it restructures social relations, charged with immense capacity and agency for action through the affordances that it contains. The player who has the ball is marked as having a special status in the game, either as a subject to attack or defend, as does the next subject/player to whom the ball travels next and is invited by the ball travelling to it to be picked up. As it moves, the subjective social relations between players become shaped by the location, possibilities or affordances of the ball, where it goes and where it has been, and where it might go next.

Thus, the ball becomes directly responsible for the framing of social relations or, in Serres' words " $t$ this quasi-object that is a marker of the subject is an astonishing constructer of intersubjectivity." 22 Crucially, Serres makes the case that the ball and the players shape, if not entirely construct, each other in tandem, and so, object and subject cannot be disentangled. The ball becomes, or is, a quasi-object, one that both defines and is defined by its relations with subjects and objects around it. 
Interestingly, while Serres illustrates what a quasi-object is by referring to a ball, Latour takes a map as his prime example to explain his concept of an immutable mobile. ${ }^{23}$ Immutable mobiles are a collection of things that retain their structure and shape while moving through spaces-times. These two figures merge in the case of mobile mapping, when we are dealing simultaneously with a mutable mobile and a quasi-object. Through the affordances of the map, an assemblage is formed that depends on fluctuating translations and relationalities. Here, the map becomes the ball. In other words, the map invites us to engage with mobile practices to produce spatio-temporal imaginative relationalities.

So mobile maps are quasi-objects with particular mobile and relational affordances. As such, they are also navigational interfaces that invite us as users to produce mobile spatio-temporal relationalities as "micro practices of power." ${ }^{24}$ Furthermore, in the case of mobile mapping as creative practice, the ludic affordances of the navigational interface are foregrounded, inviting us to produce an assemblage of quasi-objects-for example, GPS trackers, things on our path, mobile phones. ${ }^{25}$ If we work from the understanding that a ball is an interface that is designed to interact with, and possesses certain stimuli to explore further, we can define ludic interfaces as quasiobjects that invite us to play with them and give meaning to them within a larger network which is both material and immaterial. ${ }^{26,2}, 28$ The playfulness of such interfaces is intricately connected to their mobility and interactive transformability, as such interfaces invite users to visually move, perform and play with them. Furthermore, their playful agency is related to their ambiguityas a term resonating with quasi-in which a mobile map can take on multiple and paradoxical meanings, and, for example, a bridge (as urban interface) can invite you to walk over it, but also to become part of an imaginative mobile mapping practice. ${ }^{29,30}$

In the case of mobile mapping and play, all parts of the entanglement are quasi-objects. From the phone, either as a whole or a conglomerate of component parts, to the player (as bodied and virtual at once), or the material world such as architecture, green public spaces or the digital and cartographic structure of the map with its words, codes and numbers. As tendrils come together, these quasi-objects of mobile mapping make and remake, afford and designate, mark and remark in thoroughly playful ways, putting play in this assemblage.

When technologies are new, their ludic qualities are often emphasized. Whether we look at the story of the X-ray, colour cinema or more recent technologies like the Apple Watch, play often wears off after this so-called domestication of technologies. ${ }^{31,32}$ As observed by both Tuters and MacDonald, a similar tendency can be seen in relation to play and mobile mapping art. ${ }^{33}$ Around the millennium a surge of artists, designers and performers engaged with the creative and playful affordances of newly widely available technologies like GPS tracking, Google Earth, OSM, or tagging. As the newness has somewhat waned, they have become part of more mundane practices that are embedded in quotidian life, as the case of Pokémon Go so clearly shows. ${ }^{34}$ Yet that doesn't mean that the relation between artistic and mobile mapping practices has been severed altogether. As the cases below show, they have taken different forms and have hybridized to a greater extent with daily routines, in particular traversing urban environments. ${ }^{35}$ In a subtle way, they augment quotidian mobility and experiences, inviting citizens to move differently through public environments and to be moved differently by them and create different relationalities. ${ }^{36}$

\section{Bee in the City: Walking, Mapping, Playing}

In 2018, the Manchester City Council in partnership with Wild in Art, ran a major public art project to fundraise for the victims and families of victims of the 2017 Manchester Arena bombing. The project, which ran for two months, saw the construction and emplacement of over 100 large sculptural bees throughout Greater Manchester. Each bee was partnered with a local artist and sponsored by an initiative, organization or company (usually located near to the location of the bee). These artists were then asked to paint or decorate the bee as to depict a specific tenet of 
Manchester's heritage, along themes as diverse as labour movements, gay rights, industrial innovation, health and well-being, or the advertisement of the sponsor's brand.

Mobile mapping and playful experiences were central to the project. The design and placement of bees was accompanied by the production of the Bee in the City (2018) app, which enabled users to pinpoint the location of bees, unlock them, find out further information about the design, collect rewards, count steps, donate to the funding drive, and link to social media (see Figure 19.1). Importantly, in order to unlock the bees on the app, a four-digit code was required, a code that could only be found on the physical bee sculpture itself. Users had to be in place in order to mediate between the materiality of the bee and its virtual counterpart.

In doing so, mobile media like phones affords a hybridity between map and object, what de Souza e Silva has called "hybrid space." 37 The sculpture and the app can be connected through a shared location, semiotic codes, and copresence. ${ }^{38}$ Yet, what Serres' theory of the quasi-object offers is insight into how and through what this hybridization occurs-or, how things are (re) arranged. In the case of Bee in the City, hybridization is enabled by the technological capabilities of the mobile phone, specifically, its geo-location and software applications. As people use the (m)app to identify, locate, plan, and guide their route through the city, mobile media playfully produce opportunities for new paths and tours through the city. Holding the phone in your hand, deciphering which locations have been visited and unlocked and which haven't, deciding on the simplest, shortest, fastest, or most pleasant path to take, the phone becomes a quasi-object as it structures and restructures relations between people, objects, spaces and software.

Yet, in investigating the playful arrangement of things and the way in which they come together through mobile mapping, it is also possible to identify a multitude of quasi-objects, and so, multiple sites of hybridization. In Bee in the City, the bee sculpture also operated as a quasi-object, inviting different kinds of play and playful activities. Children could be seen looking around for it - and upon seeing it, letting out a squeal of delight and then climbing upon it or dancing around it. Groups would take photos (selfies or of each other) with the bee. The Queen Bee in the Royal Exchange Arcade, for example, often had queues of people waiting around for the opportunity to have a photo taken with a large bee sculpture with the face and Tudor clothing of Elizabeth I.


Figure 19.1 Queen Bee (locked), found in the Royal Exchange Arcade in central Manchester (2018). Photo credit: Wild in Art 
The app, which at first was the key guide in the search by pinpointing a location and helping a person navigate to it, becomes subordinate to the material presence of the sculpture itself. Now, the bee becomes a social and spatial constructor of intersubjectivity-also a quasi-object within itself. But, when the code is found on the bottom ledge of the sculpture, the (m)app is reengaged again. The addition of the (m)app extends the network-or "tesserae"-of quasi-objects and demi-quasi-objects: on its own the app is nothing, combined with sculptures and users it becomes part of a playful mobile mapping process, assembling and reassembling urban mobilities and flow. ${ }^{39}$

In addition, with digital-material interactivity, it becomes even more playful, producing different relations in time and space between spaces and subjects, as well as quasi-objects. The bee, the app - the entire mobile media artwork - in this way becomes a constructor of intersubjectivity. Thus, the bee sculptures as immutable and immobile, become both mobilized and mutable through the interfaciality of both the urban landscape and the mobile application. In short, Bee in the City shifted how people interacted with each other, as well as with technologies, urban materialities and artworks.

Under the gaze of the impressive neo-Georgian architecture of the library, Dazzle Bee was a relatively adorned bee, fashioned with sparkling faux jewels glued to the exterior of the sculpture. In the words of the artist, Liz Faram, it was designed so that it "sparkles and dazzles like the Manchester spirit-hard working people with energy and fire in their veins." ${ }^{40}$ It was an easy bee to find, with heavy foot traffic as bee hunters and everyday urban walkers intermingled across its path. In summer, the reflective light on its jewels made it somewhat easier to find. The four-digit code for the bee was located on the square foundation of the sculpture.

As well as the further information about both the bee and its sponsor, Daylight, the code also allowed access to the Bee Gallery, an archive of photos taken by other bee hunters. These photos usually feature images of people (and their dogs!) standing with the bee in different poses, some touching the bee, others standing loosely beside it. Here, play and the quasi-object once again become folded into mobile mapping via the artwork. The bee itself is a quasi-object, but also, so is the app: the bee gathers urban walkers towards it, through visuality, touch and location. Then, it becomes the centre-point of photographic practice, which passes engagement from the bee towards the phone and the app. A photo is taken and uploaded, which sits hybridized between the sculpture and the app, until someone else finds or comes across the bee.

Here, the playful construction and reconstruction of spatial as well as social relations becomes a central tenet of the mobile mapping practices afforded by Bee in the City (see Figure 19.2, left). At the same time, there is also space for critique of both play and mobile mapping practices as lubricants smoothing over critical concerns over the commercial and political interests of the city. The bee itself stands as an unofficial, but collectively acknowledged symbol of Manchester's industrial history and can be found repeated on the urban landscape from bollards to the architecture of the Town Hall. Following the Manchester Arena attack, 22 bees were painted in a large mural on a wall in the Northern Quarter as a memorial to the 22 people who were killed. There are multiple interpretations of the meaning of the bee symbol: from economic productivity, unionism and workers, community harmony, and more recently, innovation, creativity, and entrepreneurialism. Thus, the symbolic status of the bee-even as a quasi-object-is quite elastic and its politics, contingent on the arrangement of urban interfaces (see Figure 19.2, right).

This is apparent in subtle advertising throughout both the app and the sculptures. The sponsorship and placement of the bees are foundational to the arrangement of quasi-objects Play and mobile mapping unfold together in the exploration of space, but are also entangled in the political economy of the city itself. There was a vast range of sponsors: the National Health Service (NHS), for instance, sponsored several bees placed closed to health care providers; the LGBTIQ+ community sponsored a bee in the Gay Village. Bees were also sponsored by large corporations, such 

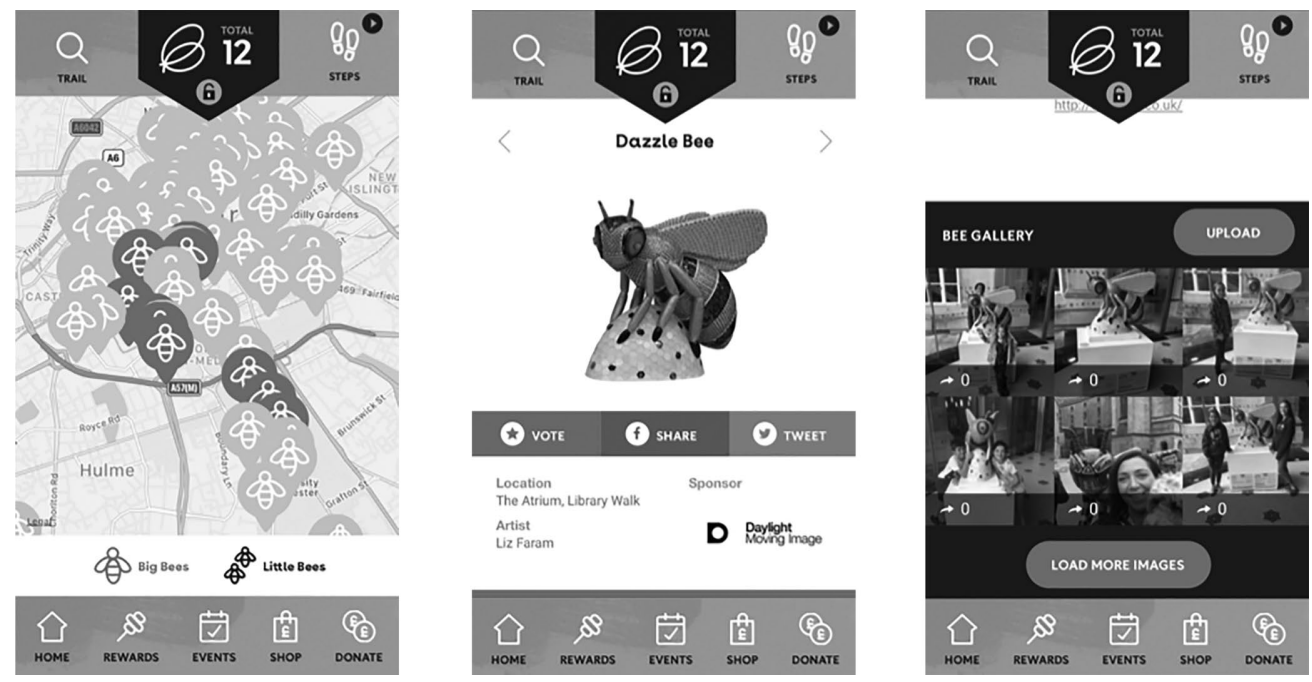

Figure 19.2 Screenshots from Dazzle Bee. Left showing the map interface, center with the unlocked bee and further information, and right showing selfies and photographs uploaded by others (2018). Photo credit: Wild in Art

as Deloitte, who have been key participants in the state-led spatial restructuring of Manchester's infrastructure along economic, rather than, say, social, lines. ${ }^{41}$ Thus, within the arrangement of quasi-objects (from the sculptures themselves to the interface and where they are placed), the politics of sponsorship - and specifically, who is sponsoring the decoration of sculptures-becomes flattened by the (m)app: community and local organization sponsors are placed with ambivalence alongside major international investment, financial and development firms that have contributed to increasing inequality within the city.

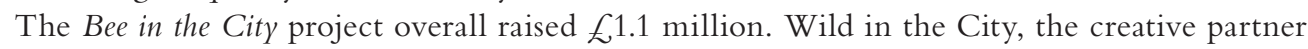
in the project, has replicated similar public art installations in cities across the world-Bristol, São Paulo, and Melbourne. ${ }^{42}$ The assembly and arrangement of quasi-objects through combinations of sculptures and mobile apps is formulaic but works precisely-as described above-because of the relationship between mobile mapping and play.

Yet, crucially, if mobile mapping is a situated practice, and play is about re-creating worlds, then the material, spatial and political specificity of the project matters. Like play itself, the symbolic meaning of the bees is ambiguous and elastic. Their status as quasi-objects lead to further ambiguity, interpreted and re-interpreted by sponsors, artists, and (m)appers. Thus, play at once opens up the creative re-exploration of the city through hybridizations of moving and looking but also might minimize or even obscure the political structures encompassed within that hybridization.

\section{Wayfinder Live: Ambiguities, Affordances and Post-Gallery Art}

In 2016 the Melbourne based artist Troy Innocent developed the Augmented Reality (AR) game Wayfinder Live, which has since been played in diverse urban environments like Bristol, Tampere, Taipei, Barcelona, and Melbourne. Dispersed through an urban environment, colourful small "tokens" or tags can be found and photographed with an app. Here the tags are foregrounded more than those on the bees in Bee in the City. Placed in sight are little panels "stitched" together in beautiful geometrical shapes attached to walls and other urban interfaces. ${ }^{43}$ Their bright colour and style contrasts with the red and grey hues of urban materials and clashes in style with fading graffiti tags. 


\section{Mobile Mapping and Play}

Similar to the bees in Manchester, this transforms the city into a playground, but also into a curated space akin to a post-digital museum. ${ }^{44}$ Also similar to Bee in the City, one does not need to engage with the sculptures via a mobile app. As these tags or codes are attached to walls and other city surfaces, even before taking our mobile devices out of our pockets or bags, we are already encountering a hybridized quasi-object of wall and visual thing which includes urban, aesthetic and playful affordances. On its own, the wall is inviting us to stop or diverge and to move in another direction. But the striking tokens-which almost look like mini-pictures on a museum wallentice us to stop and stand still. Thus, the clashing aesthetics and affordances of the token and the wall produce a new relationality for the passer-by. Together the wall and the tag, in themselves motionless and dumb, entice us to look and pause, before continuing our journey, whether as part of the Wayfinder "tour" or as a person on our way to work, or a rendezvous. In a subtle but more explicit way the tokens are quasi-object, ones that augment and aestheticize the relationality of the urban environment.

Wayfinder Live adds another mobile dimension to this playful experience. Now we have the graphic user interface (GUI) on our phone screens and are invited to turn our phones into the direction of walls and tokens. A series of translations or relationalities are set in motion, which the navigational and ludic interface on our screen-again, similar to Bee in the City, where players cross the city in different ways - create micro spatial stories through stitching the tokens together, thus creating imaginary spaces that go beyond the functionality of urban environments. Instead, the wall becomes a beacon that nudges you to a different way of traversing the urban environment and creates a new world of augmented interrelationality that the maker calls Ludea.

While Bee in the City is developed as part of a series of interactive objects whose sculptural forms are specific to the identity and culture of the city where each project is located, the Wayfinder Live artworks are portable from city to city. Arguably, the Wayfinder Live tokens are comparable to immutable mobiles. Much like Lt Cook's maps on the desk of La Perouse, their immutable form renders a continuity across time and space and between distinct urban environments. The project works based upon commonalities of the built environment, urban experience and city life. However, reconceptualizing the tokens as quasi-objects allows us to understand how the same objects become embedded and re-embedded in urban environments in ways that are both similar and unique to that city. The token is only part of the object—it is only "quasi," in that it requires the wall or the urban fabric to realize its affordances. At the same time, the wall itself is augmented by the tokens, and new affordances are generated, new possibilities explored and new situations anchored through their repositioning in different spaces and times. The mobile device is pivotal to becoming playful in the network of tokens across the city. Or as Innocent and Leorke write:

[t]he ways in which they influence walking, navigation, and exploration of the city; [...] is a way of decoding the city so as to perceive it as a process or system, leading players to reimagine or reinvent the city through their play experience..$^{45}$

They emphasize the way in which the processuality of the city as a system is laid bare via the playful Wayfinder app. The figure of the quasi-object adds yet another layer to this analysis as it allows us to understand the mobile device, or more precisely the GUI of Wayfinder, as not only inviting us to decode and reimagine the city, but also to produce new relationalities in which both the tokens and the app figure as quasi-objects, inviting us to spin micro stories that are assemblages of all kind of stuff. ${ }^{46}$ Crucial to this is that the tokens and the app do more than just adding another layer to urban interfaces such as walls: they transform them into ludic and navigational interfaces, thus inviting us to approach them as ambiguous in use (is it a wall or a plaything?) and inviting us to produce new mobilities and spatial stories. This is where mobility, play and mapping forge new and creative relationalities. 


\section{Conclusion: Hope and Failure}

This chapter has considered how the relationship between mobile mapping and play affords possibilities for reassembling social and spatial relations in mobile media art. Using Serres' concept of the quasi-object, we map how the hybridization of both mapping and play has resulted in an extensive collection of actors-from technologies to users, material objects and architectures. Artworks that leverage the combined act of looking at shifting maps on mobile interfaces while touring around the city offer the opportunity to restructure urban relations, even if only temporarily, creating different navigational practices and spatial engagements. Furthermore, reading these formulations through the lens of the quasi-object, it becomes clear that mobile media art projects that use the combination of play and mobile mapping have the potential to turn the city into a playground through the hybridization of touring and looking.

We have explored the relation between art and mapping, especially in relation to play and mobility. We have argued that mapping and creativity have always had an intricate compatibility and share a long history, which has often been denied in the past in a bid to propagate the idea of maps as objective or serious, thus denying both an understanding of mapping as a hybrid and mobile practice, and being blind to the seriousness that play can harbour. ${ }^{47}$ The intimate connection between mapping, play and mobility is in particular foregrounded in artistic mapping practices like locative art.

At the same time, following Sutton-Smith, we argue that the ambiguity of play may act as a force that de-politicizes, re-politicizes, or erases critical concerns about those social and spatial relations within mobile mapping and urban navigational mobilities. ${ }^{48}$ This is hinged on precisely how different quasi-objects are arranged and formed through mobilities, interactions and explorations. In the case of Bee in the City, the bee sculptures invite a re-engagement of urban touring through locating and unlocking bees, participating in divergent urban practices on a social scale, uploading and sharing experiences generated through the artwork via the app. Yet, these playful mobile mappings also smoothed over the economic structure of sponsorship that enabled the project to come into fruition. In doing so, it also smoothed over the economic and political inequalities embedded in Manchester's urban processes and development, flattening large corporate interests into the same level as local community organizations through the linguistic, semiotic and spatial arrangement of the interface and the sculptures. Thus, play at once makes visible the presence of these corporate interests within the city through branding, but also makes them invisible by relegating them to the edge, and obscuring urban economic inequalities.

Comparably, in the example of the Wayfinder Live app, the clandestine, hidden and mundane parts of the city become key spaces in hybrid play. Yet, Wayfinder Live engages far more directly and critically with the already existing material architectures of the city. Compared to the symbolic decoration of the bees as facets of Manchester's identity, the geometric tokens invite various kinds of urban engagement. Tokens can be found on walls of different textures and materials, requiring users to directly engage with the multitude of materialities, spaces and places of the city.

Using two case studies we have identified how mobile media art playfully uses complex arrangement of quasi-objects to open up opportunities to remap and reencounter urban environments. We argue that while the assembly and arrangement of quasi-objects is playful, how these quasi-objects are arranged is often intensely political in ways that are deeply contingent on the mobilities, technologies and socio-spatial relations involved. Therefore, when we consider how play and mobile mapping may operate in post-digital environments, we argue that it is absolutely crucial to consider how digital and material politics become folded into how quasi-objects are arranged.

The hybridization of quasi-objects, or even their arrangement, while also allowing a plurality of interpretation and action, may also present only a singular or partial interpretation, stripped of political, situated or cultural meaning. Thus, in analysing the political and social consequences of 
mobile media art using mobile mapping and play, the way in which quasi-objects are assembledand the limitations placed on their affordances-is crucial. This is magnified by the ambiguity of play itself.

Moving away from the notion of maps as being too static a notion to analyse such practices, we wanted to emphasize the "ings of things" in this chapter and focus on processes of translations and processuality that are pivotal to such artworks. ${ }^{49}$ In the same vein, we approached artistic mapping practices as a network of quasi-objects with particular mobile and relational affordances that are both playful and mobile. Their mobility lies in their capacity to invite users to move in different ways and their navigational affordances to produce micro spatial narratives as assemblages. Their playfulness is related to their ambiguity in which a bee can become simultaneously a sculpture, playful beacon, and advertisement or a tag on a wall, transforming its surface in a more ambiguous urban interface with more than one meaning. Thus, new interrelationalities are spun that are situated and work between different planes of (urban) environments. That is, if the passer-by wants to pick up on this. Otherwise there is nothing and mobility and play do not bring a collective into being.

Here, we make a final argument: in mobile mapping and play, politics are played out through relations and relationality. Furthermore, the quasi-object is neither political nor apolitical. Instead, it is both at once: it holds numerous possibilities for action and for structuring intersubjectivitiesall, some or none of which may be realized. This realization is dependent on the collection of other objects, subjects or quasi-objects that come into contact with the quasi-object. This is evident in the similarities and disparities of both the case studies discussed: the urban, social, spatial and economic contexts, where and how sculptures are placed, what the app invites or asks, all shape the broader consequences, social impact, and engagement of mobile media art.

\section{Notes}

1 Brian Quinn and William Cartwright, "Geographic Board Games," Proceedings of the 2014 Geospatial Science Research 3 Symposium (GSR_3), 2-3 December 2014 Melbourne Australia.

2 Marc Tuters and Kazys Varnelis, "Beyond Locative Media: Giving Shape to the Internet of Things," Leonardo 39, no. 4 (2006): 357-63. doi: 10.1162/leon.2006.39.4.357.

3 Gavin Macdonald, "Traces, Tiles and Fleeting Moments: Art and the Temporalities of Geomedia," in Time for Mapping: Cartographic Temporalities, edited by Alex Gekker, Sam Hind, Sybille Lammes, Chris Perkins, Clancy Wilmott, and Daniel Evans (Manchester: Manchester University Press, 2018), $138-53$.

4 Ester Polak, Jerome Kee and Waag Society, Amsterdam Real Time: a Diary in Traces. 2002.

5 Johan Huizinga, Homo ludens: proeve eener bepaling van het spel-element der cultuur (Amsterdam: Amsterdam University Press, 1938), 199.

6 Sybille Lammes, "Destabilizing Playgrounds: Cartographical Interfaces, Mutability, Risk and Play," in Playful Disruption of Digital Media, edited by Daniel Cermak-Sassenrath (Singapore: Springer, 2018): 87-98.

7 Sybille Lammes and Clancy Wilmott, "The Map as Playground: Location-Based Games as Cartographical Practices," Convergence: The International Journal of Research into New Media Technologies 24, no. 6 (2016): 648-65, doi: 10.1177/1354856516679596.

8 Mihaly Csikszentmihalyi, "Play and Intrinsic Rewards," Journal of Humanistic Psychology 15, no. 3 (1975): 41-63, doi: 10.1177/002216787501500306.

9 Brian Sutton-Smith, "The Epistemology of the Play Theorist," Behavioural and Brain Sciences 5, no. 1 (1982): 170-71.

10 Brian Sutton-Smith, The Ambiguity of Play (Cambridge, MA: Harvard University Press, 2001).

11 Miguel Sicart, Play Matters (Cambridge, MA: The MIT Press, 2014), 2.

12 Miguel Sicart, "Quixotean Play in the Age of Computation," American Journal of Play 10, no. 3 (2018): 262.

13 Clancy Wilmott, Mobile Mapping: Space, Cartography and the Digital (Amsterdam: Amsterdam University Press, 2019).

14 J. B. Harley, “Deconstructing the Map," Cartographica 26, no. 2 (1989): 1-20. 
15 Chris Perkins, "Performative and Embodied Mapping," in International Encyclopedia of Human Geography, edited by Rob Kitchin and Nigel Thrift (London: Elsevier, 2009), 126-132.

16 Clancy Wilmott, “In-Between Mobile Maps and Media: Movement," Television \& New Media 18, no. 4 (2016): 320-35.

17 Sybille Lammes and Chris Perkins, "An Introduction to Playful Mapping in the Digital Age," in Playful Mapping in the Digital Age, edited by Playful Mapping Collective (Amsterdam: Institute of Network Cultures, 2016), 12-27.

18 Sybille Lammes, "Digital Mapping Interfaces: From Immutable Mobiles to Mutable Images," New Media E Society 19, no. 7 (2017): 1019-33, doi: 10.1177/1461444815625920.

19 Michel Serres, The Parasite (Minneapolis: University of Minnesota Press, 2007), 224-35.

20 Ibid., 224.

21 Ibid.

22 Ibid., 227.

23 Bruno Latour, "Visualization and cognition: Drawing things together," Knowledge and Society 6 (1986): 1-40, doi: 10.22394/0869-5377-2017-2-95-15.

24 Kim Dovey and Stephen Wood, "Public/Private Urban Interfaces: Type, Adaptation, Assemblage," Journal of Urbanism: International Research on Placemaking and Urban Sustainability 8, no. 1 (2015): 1-16, doi: 10.1080/17549175.2014.891151.

25 Sybille Lammes and Clancy Wilmott, "The Map as Playground: Location-based Games as Cartographical Practices,” Convergence 25, no. 6 (2016): 648-65, doi: 10.1177/1354856516679596.

26 James Gibson, The Ecological Approach to Visual Perception (New York: Psychology Press, 2015); Donald Norman, The Design of Everyday Things, Revised and Expanded Edition (Cambridge, MA: The MIT Press, 2013).

27 Mathias Fuchs, "Ludic Interfaces. Driver and Product of Gamification," $G|A| M \mid E$ The Italian Journal of Games Studies 1, no. 1 (2012): 19-26.

28 Latour, "Visualization and Cognition."

29 Sutton-Smith, The Ambiguity of Play.

30 Dovey and Wood, "Public/Private Urban Interfaces."

31 Clancy Wilmott, Emma Fraser and Sybille Lammes, “I Am He. I Am He. Siri Rules': Work and Play with the Apple Watch," European Journal of Cultural Studies 21, no. 1 (2017): 78-95, doi: 10.1177/1367549417705605.

32 Jean Burgess, "The iPhone Moment, the Apple Brand, and the Creative Consumer: From 'Hackability and Usability' to Cultural Generativity," in Studying Mobile Media: Cultural Technologies, Mobile Communication, and the iPhone, edited by Larissa Hjorth, Ingrid Richardson and Jean Burgess (London: Routledge, 2012), $28-42$.

33 Marc Tuters. "From Mannerist Situationism to Situated Media," Convergence 18, no. 3 (2012): 267-82, doi: 10.1177/1354856512441149; Gavin MacDonald, "Moving Bodies in the Inhabitable Map: The GPS Trace in New Media Art," PhD Thesis, Manchester Metropolitan University (2012).

34 Larissa Hjorth and Ingrid Richardson, "Pokémon GO: Mobile Media Play, Place-Making, and the Digital Wayfarer," Mobile Media and Communication 5, no. 1 (2017): 3-14, doi: 10.1177/2050157916680015.

35 Adriana de Souza e Silva and Larissa Hjorth, "Playful Urban Spaces: A Historical Approach to Mobile Games,” Simulation \& Gaming 40, no. 5 (2009): 602-25, doi: 10.1177/1046878109333723.

36 Monika Büscher, "Moving Methods," in Routledge Handbook of Interdisciplinary Research Methods, edited by Celia Lury, Rachel Fensham, Alexandra Heller-Nicholas, Sybille Lammes, Angela Last, Mike Michael, and Emma Uprichard (London: Routledge, 2018), 167-82.

37 Adriana de Souza e Silva, "From Cyber to Hybrid: Mobile Technologies as Interfaces of Hybrid Spaces," Space and Culture 9, no. 3 (2006): 261-78, doi: 10.1177/1206331206289022.

38 Mizuko Ito, Daisuke Okabe, and Misa Matsuda, Personal, portable, pedestrian: Mobile phones in Japanese life (Cambridge, MA: The MIT Press, 2005).

39 Serres, The Parasite, 233.

40 Wild in Art and Manchester City Council, Bee in the City, Manchester, 23 July to 23 September 2018, https://beeinthecitymcr.co.uk/.

41 Mike Hodson, Simon Marvin and Andy McMeekin, "The Amenable City-Region: The Symbolic Rise and the Relative Decline of Greater Manchester's Low Carbon Commitments, 2006-2017," in Rethinking Urban Transitions: Politics in the Low Carbon City, edited by Andrés Luque-Ayala, Simon Marvin, and Harriet Bulkeley (London: Routledge, 2018), 91-106.

42 Wild in Art, 2018.

43 Dovey and Wood, "Public/Private Urban Interfaces." 
44 Lissa Holloway-Attaway and Rebecca Rouse, "Designing Postdigital Curators: Establishing an Interdisciplinary Games and Mixed Reality Cultural Heritage Network," in Advances in Digital Cultural Heritage, edited by Marinos Ioannides, João Martins, Roko Žarnić, and Veranika Lim (New York: Springer, 2018), 162-73.

45 Troy Innocent and Dale Leorke, "Heightened Intensity: Reflecting on Player Experiences in Wayfinder Live,” Convergence 25, no. 1 (2019): 18-39, doi: 10.1177/1354856518822427.

46 Michel de Certeau, The Practice of Everyday Life (London: Routledge, 1984).

47 Huizinga, Homo ludens.

48 Sutton-Smith, The Ambiguity of Play.

49 Celia Lury, Rachel Fensham, Alexandra Heller-Nicholas, Sybille Lammes, Angela Last, Mike Michael and Emma Uprichard (eds), The Routledge Handbook of Interdisciplinary Research Methods (London: Routledge, 2018). 